\title{
Gemfibrozil reduced the risk for stroke in men with coronary heart disease and low concentrations of high-density lipoprotein cholesterol
}

\author{
Rubins HB, Davenport J, Babikian V,et al, for the VA-HIT Study Group. Reduction in stroke with gemfibrozil in men with \\ coronary heart disease and low HDL cholesterol. The Veterans Affairs HDL Intervention Trial (VA-HIT). Circulation \\ 2001 Jun 12;103:2828-33.
}

QUESTION: In men with coronary artery disease and low concentrations of high-density lipoprotein (HDL) cholesterol, is gemfibrozil effective for preventing stroke?

\section{Design}

Randomised \{allocation concealed*\}†, blinded \{patients, outcome assessors, and study personnel $\} \uparrow *$ placebocontrolled trial with mean 5.1 years of follow up (Veterans Affairs HDL Cholesterol Intervention Trial [VA-HIT]).

\section{Setting}

20 Veterans Affairs medical centres in the USA.

\section{Patients}

2531 men who were $<74$ years of age (mean age $64 \mathrm{y}$ ) and had a confirmed diagnosis of coronary artery disease, an HDL cholesterol level $<1.03 \mathrm{mmol} / \mathrm{l}$, a lowdensity lipoprotein cholesterol level $<3.6 \mathrm{mmol} / \mathrm{l}$, and a triglyceride level $<3.39 \mathrm{mmol} / \mathrm{l}$. Follow up was complete.

\section{Intervention}

1264 men were allocated to gemfibrozil $1200 \mathrm{mg} / \mathrm{d}$, and 1267 were allocated to placebo. $†$ The patients were seen every 3 months by the study coordinator.

\section{Main outcome measures}

Incidence of first strokes and fatal strokes.

\section{Main results}

$\{$ Analysis was by intention to treat. $†$ Fewer patients who received gemfibrozil had a stroke than did patients who received placebo $(\mathrm{p}=0.036)$ (table). The groups did not differ for fatal strokes (3 [0.2\%] v $9[0.7 \%],\{\mathrm{p}=0.15\}$ ). $90 \%$ of all strokes were ischaemic, and the greatest benefit of gemfibrozil was seen in a reduction of atherothrombotic strokes $(3$ [5\%] $v 16$ [21\%], \{unadjusted $\mathrm{p}=0.0028\} \S)$.

\section{Conclusion}

In men with coronary artery disease and low concentrations of high-density lipoprotein cholesterol, gemfibrozil reduced the risk for stroke.
*See glossary.

$†$ Rubins HB, Robins SJ, Collins D, et al. N Engl J Med 1999;342:410-8.

$\$ \mathrm{p}$ Value provided by author.

$\S p$ Value calculated from data in article.

\section{COMMENTARY}

The study by Rubins $e t$ al is important because it is the first to show that in patients with coronary artery disease, the risk for subsequent stroke (mainly non-fatal atherothrombotic stroke) may be reduced with a fibrate (in this case, gemfibrozil). The results of this study need to be put in the context of similar findings in patients with coronary artery disease who were treated with a statin.

Although the clinical characteristics of the patients in both studies were reasonably similar, Rubins et al recruited patients in whom the predominant lipid abnormality was a low HDL level; however, the investigators of the LIPID (Long-Term Intervention with Pravastatin in Ischaemic Disease) study recruited patients with a broad range of cholesterol concentrations.

What does this mean to practising clinicians? In essence, we now have a choice of agents that may be useful in protecting patients with coronary artery disease from stroke. One could argue that gemfibrozil may be more helpful in patients with low HDL concentrations, but a more general effect has not been ruled out. As yet, we have no information about whether protection shown in either trial is a class effect or relates to each agent specifically. Similarly, we do not know the effect of combining these agents. As is often the case, this study represents a promising development, but more questions need to be answered.

Geoffrey A Donnan, MD

National Stroke Research Institute Melbourne, Victoria, Australia

White HD, Simes RJ, Anderson NE, et al. Pravastatin therapy and the risk of stroke. N Engl J Med 2000;343:317-26.

Gemfibrozil v placebo for preventing strokes in men with coronary artery disease and low high-density lipoprotein cholesterol at mean 5.1 years

\begin{tabular}{lllll} 
Outcome & Gemfibrozil & Placebo & Adjusted RRR $(95 \% \text { Cl) })^{\text {** }}$ & NNT (CI) \\
All strokes & $4.6 \%$ & $6.0 \%$ & $31 \%(2$ to 52$)$ & 55 (33 to 688$)$ \\
\hline
\end{tabular}

IAbbreviations defined in glossary; NNT and Cl provided by author.

${ }^{* \star}$ Adjusted for baseline variables. 